Postgrad. Med. J. (1966), 42, 703.

\title{
AIR POLLUTION, BRONCHITIS AND LUNG CANCER
}

\author{
P. J. Lawther, M.B., F.R.C.P. \\ Director, M.R.C. Air Pollution Research Unit, St. Bartholomew's Hospital Medical College, London, E.C.1
}

THE RELATIONSHIP of air pollution to disease is complex. The topic provokes emotional attitudes in many and is of political and economic importance. Much confusion exists regarding the nature of pollution and its real or suspected effects on man and this essay is written in order to try to lessen the confusion rather than to provide a formal review of the subject.

For many centuries British urban air has been contaminated by the products of combustion of coal; industrial processes have added their contribution and in this country we have seen the addition of pollution from the burning of petroleum. Ideally, carbon-containing fuels should yield only carbon dioxide and water when burned but usually many other compounds are emitted. These may be produced as a result of incomplete combustion, distillation of volatile matter, combustion of impurities in the fuel or fixation of atmospheric nitrogen. If some chemically simple fuel such as natural gas is burned in an inadequate supply of air smoke consisting of fairly pure carbon (lamp black) and carbon monoxide would be produced in addition to the carbon dioxide and water. One would also expect to find traces of polycyclic aromatic hydrocarbons formed by pyrolysis. If the gas contained sulphur compounds, sulphur dioxide would be emitted in company with smaller amounts of sulphur trioxide if the temperature of combustion were high enough. If the gas, or indeed any fuel, were burned at high temperature and under pressure significant fixation of atmospheric nitrogen would occur and oxides of nitrogen would be emitted. The production of oxides of nitrogen is greater when temperature and pressure are high and the reaction products are removed rapidly from the zone of combustion. High compression ratio internal combustion engines produce oxides of nitrogen in this manner.

The combustion of coal is more complicated; when coal is burned in the grossly inefficient domestic open grate a series of stages in the emission of pollutants may be recognised. When a shovelful of coal is added to a hot fire much volatile matter is distilled off and is manifest as greenishyellow tarry smoke containing very little soot since it is not a product of combustion. Eventually $\overrightarrow{\vec{\omega}}$ some of the volatile matter which includes coal gas $\stackrel{\circ}{\omega}$ ignites and burns incompletely with a yellow smoky. flame. Later the carbon residue - which is indeed 3 coke - burns smokelessly; at this stage much of the pyrites is decomposed with the resultant emission of oxides of sulphur. The thermales efficiency of the domestic grate is very low indeed.

Industry could not tolerate anything like the inefficiency so widely accepted in domestic heating 윽 and the pollution produced by industrial coal-burning plants differs accordingly; a boilerman tries $z$ to achieve as near complete combustion as possible and the concentrations of carbon dioxide, oxygen 3 and carbon monoxide in fuel gases are carefuity monitored with this object; the emission of blas smoke is indicative of gross failure to achieke. economic combustion and the production of tare volatile matter such as that emitted by the domestic distillation of coal is virtually impossible in any but the smallest furnaces. In general it can be said that oil is more easily burnt without smoke production since it can be dispersed in fine droplets or as $a \stackrel{\square}{\circ}$ vapour so that combustion may be more efficient. $\overrightarrow{\vec{B}}$

There is a further distinction between domestic 3 and industrial pollution which is highly relevant to the study of its clinical effects; pollution from? domestic sources is emitted at low level whilst industrial stacks are usually high enough to avoid 3 . gross contamination of the air at ground level. Figures frequently quoted relating to gross emissions of various pollutants may therefore be whollyo irrelevant to the study of their effects for it is the concentration at ground level which is important. 을

Ground level concentrations are of course influenced by the amount of pollutant emitted as well as the height of the source but an even more N important factor is the weather. Normally pollutants are dispersed into the upper air by the $\tilde{D}$ buoyancy of the plume and by the upward move- $\omega$ ment of warm air from the ground; they are also greatly diluted by wind. Episodes of extraordinarilyo high air pollution occur during the temperature $\overparen{\varnothing}$ inversions which accompany winter anticyclones. ? Then the normal turbulence of the air near the 70 ground ceases and stagnation results. Pollutants 


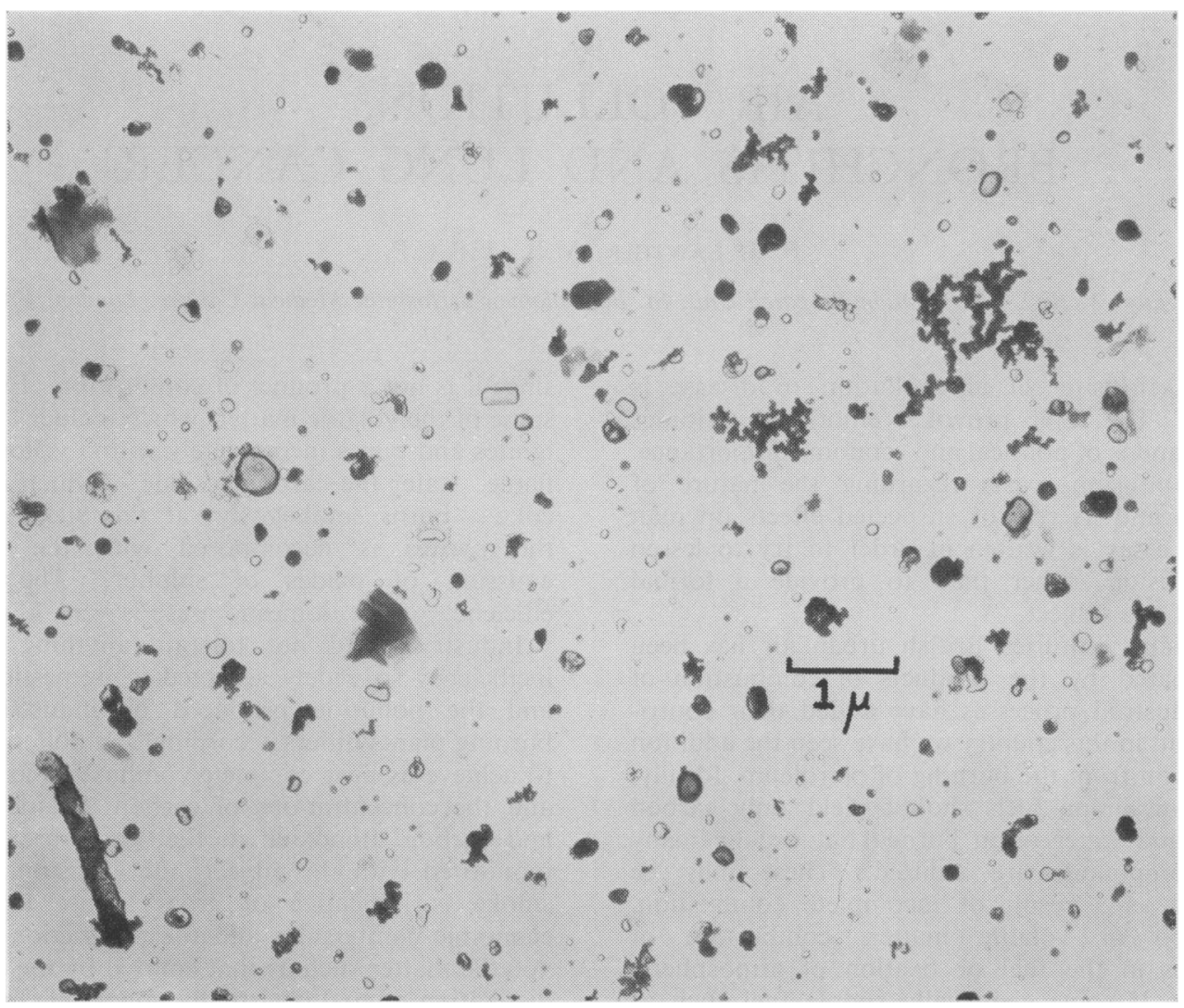

FIG. 1.-Electron micrograph of general pollution $\times 11,000$.

emitted near the ground accumulate but some plumes, although originating below the inversion level, may, by virtue of their velocity and buoyancy, pierce the ceiling and be dispersed by the winds aloft. Fog frequently accompanies these temperature inversions and the water droplets of which it is composed impair the dispersion processes and in addition favour the oxidation of sulphur dioxide to sulphuric acid.

Air pollution is measured widely in this country, generally over periods of 24 hours, in terms of smoke (determined from the stain on a filter paper) and sulphur dioxide. These measurements are valuable for epidemiological research but more detailed investigations are necessary for experimental work.

Particulate matter in the air has been the subject of intensive study by means of optical and electron microscopy (Fig. 1). Average and maximum concentrations of various common pollutants are given in Table 1.

Pollution may produce, or may be suspected of producing, several effects on man. Episodes of especially high pollution are accompanied by sharp increases in mortality and morbidity. The deaths and illness occur among the feeble members of the community - the very young and old, and those suffering from cardio-vascular or respiratory disease. These episodes are often mentioned by patients as marking, or causing, the onset of their chronic bronchitis; repeated exposure to high pollution or chronic exposure to "chronic" pollution has been blamed, with fair reason, for causing chronic bronchitis and lung cancer. These effects or suspected effects will be considered critically.

Undoubtedly the clearest connection between air pollution and disease is seen during the episodes of intense pollution. Distress among patients with chronic bronchitis is common (though not all are affected) and is usually manifest by cough, wheezing and increased dyspnoea. The effects would seem to be due to increase in airway resistance in response to irritation. An immense amount of work has been done in many centres in an effort to identify the irritant component. Much attention has been 
TABLE 1

MAXIMUM AND TYPICAL WINTER CONCENTRATIONS OF SOME POLLUTANTS MEASURED IN CENTRAL LONDON, 1954 - 64

$\begin{array}{lcc} & \text { Maximum } & \text { Typical winter } \\ \text { Sonc. } & \text { conc. } \\ \text { Carbon monoxide (p.p.m.) } & 10 & 0.2 \\ \text { Sulphur dioxide (p.p.m.) } & 360 \times & 10 \times \\ \text { Sulphuric acid (mg/cu. mm.) } & 2.0 & 0.2 \\ \text { Nitric oxide (p.p.m.) } & 0.7 & 0.01 \\ \text { Nitrogen dioxide (p.p.m.) } & 1.1 & 0.05 \\ \text { 3:4-benzpyrene ( } \mu \text { g/100 cu. mm.) } & 0.2 & 0.03 \\ & 222 & 5\end{array}$

$\times$ As measured close to traffic in busy streets: concentration much lower in general atmosphere.

focussed on sulphur dioxide as the most likely chemical irritant but unfortunately it has all been too uncritically accepted as the compound which causes the damage. Thousands of experimental exposures have been made in laboratories in many parts of the world and there is yet little convincing evidence that sulphur dioxide in concentrations which might be found in town air (up to 2 parts per million) can cause the increases in airway resistance observed in clinical practice. There are of course asthmatic subjects who are especially sensitive to sulphur dioxide but rarely if ever have they been shown to react consistently to concentrations of $2 \mathrm{ppm}$. $\mathrm{SO}_{2}$. Obviously some combination of pollutants, gaseous or particulate, is more likely to be the culprit than a single substance. Combinations of sulphur dioxide and sulphuric acid mist (in realistic concentrations) have been tried, hitherto without success, and following the demonstration by Mary Amdur (1959) of a synergistic action of sulphur dioxide and salt aerosols on the airways resistance of guinea pigs. Much experimental work on human subjects has been done to see how findings could be reproduced in man. Experiments in this country and by Mary Amdur and her associates have failed to demonstrate the effect on human subject.

We have thought it possible that sulphuric acid might be the irritant but that in laboratory experiments which failed to produce increase in airway resistance the failure might have been due to the rapid dilution of the acid droplets on entering the warm humid respiratory tract. Experiments which "protected" acid, in which porous particles of charcoal have been inhaled after having been refluxed with sulphuric acid, have so far failed to give positive results; they are continuing. Another set of experiments in progress in the M.R.C. Unit is casting further doubt on the importance of sulphur dioxide alone. Airway resistance measurements (made in the whole body plethysmograph) are made daily on two subjects immediately on arrival at the laboratory after a walk of nearly two miles through the City.
A correlation is demonstrable between pollution in terms of smoke or sulphur dioxide in one subject 3 . who is unaffected by experimental inhalations of $\stackrel{+}{\sim}$ $30 \mathrm{ppm} \mathrm{SO}_{2}$, whereas there is no relationshipe between pollution and airway resistance in a col- $\omega$ league who is sensitive to sulphur dioxide in con- $\supset$ centrations greater than $5 \mathrm{ppm}$. These experiments $\omega$ are in their early stages but a pattern is emergingfrom these results and the results of hundreds of experimental inhalations which indicate that theo principle irritant is far from simple in chemical orळ physical nature.

There is, of course, an urgent need to identify the irritant so that its emission may be prohibited $8 \mathrm{r}_{\overrightarrow{0}}$ diminished. The Clean Air Act (1956) prohibits the emission of smoke in specified areas but it is powe less to deal with sulphur dioxide (so far no remotelyo economic means have been found to remove this pollutant at source) and it is of obvious importance to determine whether or not the improvements in the quality of air as a result of the implementation of the Act will be sufficient to diminish the likelihood $\overrightarrow{\overrightarrow{0}}$ of a repetition of the 1952 London "smog." Techniques other than those used in the laboratory are being employed and these exploit the fact that the concentration of smoke is diminishing whilsto the sulphur dioxide content remains virtually unchanged. For several years the relationship 3 between pollution (measured in terms of smoke and sulphur dioxide concentrations) and mortality from $\mathrm{O}$ chest and heart diseases, and morbidity (measured in terms of requests to the Emergency Bed Service 5 for admission to hospital for respiratory or cardiac causes) have been studied. In addition, a further group of specially selected patients have been taking ${ }_{\sigma}^{N}$ part in a series of winter experiments. In these $\mathrm{N}$ experiments groups of volunteer chronic bronchitic N patients from Chest Clinics in London have been ${ }^{\omega}$ recording daily their own assessment of their con-₹ dition as "better," "same" or "worse" than the dayc before the diary entry. These results have been $\cong$ plotted against daily measurements of smoke,,$_{+}^{+}$ sulphur dioxide, visibility, temperature and 
humidity. The early "diary" experiments showed a remarkably close correlation between smoke and sulphur dioxide and the well-being of the group of patients (Lawther (1958)). The experiments have been continued, as have the surveys of morbidity and mortality, in order to study the possible diminution in correlation with pollution as smoke concentrations diminish. These experiments and surveys need not only many subjects but many variations in pollution before results can be produced which will indicate with any certainty in which group of pollutant this irritant lies but, though much analysis of current work remains to be done, there are already indications that the morbidity and mortality would seem to be related less closely than formerly to changes in pollution. The results to date would favour the hypothesis that the substance or combination of substances causing exacerbations of existing chest disease is related more closely to smoke than to sulphur dioxide. The application of computer techniques to the results obtained over the last 10 years may be surprisingly fruitful in that they may enable the reactions of separate individuals or groups of individuals to different combinations of pollution and weather to be identified.

Chronic bronchitis is found more commonly in towns than in country districts and its prevalence is fairly closely related to air pollution (more accurately to some supposed index of pollution such as "fog frequency," coal consumption per unit area or to population density). The supposition is, therefore, that air pollution plays an important role in the production of chronic bronchitis. Again, both smoke and sulphur dioxide have been blamed often on wholly inadequate evidence. Chronic bronchitis is a disease (or even more than one disease) with an ill-defined time of onset and a long natural history which may or may not merge with that of asthma, emphysema, and bronchiectasis. And few would claim that air pollution is the only noisome feature of urban life which need be suspected of causing the disease. Because of the clinical and epidemiological complexities of the problem the development and use of the M.R.C. Questionnaire on Respiratory Symptoms is most welcome for by its application and the use of simple pulmonary function tests the prevalence of symptom complexes, rather than diagnosis, can be estimated. By means of this technique Stuart-Harris and Hanley (1957) showed that in Sheffield and in rural Wensleydale simple bronchitis - the presence of chronic cough with the expectoration of mucoid sputum was related to cigarette smoking rather than any other measured factor. This important finding was confirmed by the College of General Practitioners (1961) who showed, in addition, that complicated bronchitis - with expectoration of purulent phlegm accompanied by recurrent chest infections and dyspnoea - was related to an urban factor rather than cigarette smoking.

These important findings might seem at first sight to be at variance with the history of pathological change in chronic bronchitis as demonstrated by Lynne Reid (1958). Undoubtedly the early stages of chronic bronchitis are characterised by the hypersecretion of mucus and the appropriate hypertrophy of mucus-secreting tissue. Some would assume that this hypertrophy and hypersecretion is in response to the irritant air of our cities yet it is obvious that there is in the air no simple chemical irritant powerful enough to produce these changes. Cigarette smoke is a powerful irritant and fits the hypothesis well. There is a greater likelihood that air pollution is the urban factor, or one of the urban factors, involved in the transformation of simple chronic bronchitis into the far more serious infected complicated phase of the disease. Such a factor need not be irritant at all. It could be a substance that favours the development or persistence of infection either by interference with the cleansing of the respiratory tract or by actually encouraging the growth of $\boldsymbol{H}$. influenzae or Strep. pneumoniae. Preliminary experiments in the M.R.C. Unit have shown that, at least, extracts of smoke do not inhibit the growth of these organisms.

The hypothesis that chronic bronchitis is caused by simple chemical irritation afforded by air pollution is barely tenable in the absence of notorious excesses of the disease in workers in industries where high concentrations of chemical irritants are inhaled.

A recent study by Douglas and Waller (1966) provides a refreshing break from the obsession with sulphur dioxide acting as an irritant sufficiently powerful to cause bronchitis in the general population and underlines the obvious fact that the cause of the disease is likely to be much more subtle. Douglas started a unique survey by following up 5,362 children born during the first week of March 1946. The frequency of upper and lower respiratory tract infections was noted in addition to many other clinical features. Waller estimated the childrens' likely exposure to pollution and allotted them to four pollution categories. Analysis of the results showed that there was no apparent correlation between the occurrence of upper respiratory tract infections in infancy and pollution category but, in all social classes the occurrence of lower respiratory tract infections was related to pollution category. The oft-demonstrated correlation with social class (independent of pollution category) was also seen.

The prospect of success in displaying in full the aetiological factors in chronic bronchitis by the use of epidemiological methods is not very bright since the disease is prolonged and multifactorial 
and the environmental (and demographic) factors are altering too quickly to enable a complete picture to be built up. Such techniques are however invaluable for the comparison of prevalence in different countries (such as the U.S.A. and Britain) and in different occupational groups.

Lung cancer is commoner in towns than in the country. So is soot. And soot, which caused cancer of the scrotum in chimney sweeps in Percival Potts' time contains carcinogenic polycyclic aromatic hydrocarbons. Sir Ernest Kennaway's team brilliantly isolated and identified from coal tar the chemical carcinogen 3:4-benzpyrene. Several other hydrocarbons in coal tar, and in coal smoke, are potent carcinogens and it would seem wholly reasonable to attribute the skin cancer of chimney sweeps, tar workers and mule spinners to the action of polycyclic hydrocarbons. The temptation to attribute lung cancer to air pollution is great since coal smoke is a rich source of polycyclic hydrocarbons. There are, however, many serious objections to such simple hypotheses. Lung cancer is a disease which has been becoming commoner since the turn of the century and the rise is still continuing. Certainly part of the early reported rise in the incidence of the disease was artificial and was due to the more widespread use of diagnostic radiology and to greater awareness of the existence of the disease as a pathological entity. There was until the 1940's much speculation regarding the validity of the observed increase but for many years it has been apparent that the increase in the prevalence of the disease is all too real. The increase has been mainly in tumours of the squamous and oat cell types, many authorities believing that the frequency of adenocarcinomata has remained relatively unchanged. Throughout the period during which lung cancer has increased pollution by coal smoke has decreased steadily.

If polycyclic aromatic hydrocarbons were responsible for lung cancer in man one might expect to find great excesses of the disease among those who by virtue of their occupation have inhaled large quantities of these compounds. As has already been said the distillation and incomplete combustion of coal produces tar rich in polycyclic hydrocarbons and in the past some excess of lung cancer in retorthouse workers in gas works have been reported by several workers. Recently Doll and the Medical Officers of several Regional Gas Boards have studied the mortality from lung cancer of gas workers (1965) whilst the M.R.C. Unit (Lawther, Commins, and Waller, 1965) defined the environment in terms of polycyclic hydrocarbons. This work showed that certain workers in the old horizontal retort-house were exposed to concentrations of 3:4-benzepyrene about one thousand times greater than the winter average found in large towns. One would have expected to find a spectacular excess mortality from lung cancer in such an occupation yet the excess, though demonstrable, was small and in no sense commensurate with the vast excesses of $3: 4$-benzepyrene in the environment.

The urban/rural discrepancy in lung cancer mortality in Britain has been used as powerful evidence in favour of the hypothesis that air pollution causes lung cancer. Similar urban/rural ratios are to be found in countries in which air pollution is nominal. Finland has the second highest lung cancer mortality in the world yet its air, in town and country, is very poor in hydrocarbon content. Similar urban/rural gradients in lung cancer mortality are seen in Norway and in many other clean countries.

In recent years there has been an outcry against pollution from motor vehicles especially those powered by diesel engines which has been blamed by many for the rise in lung cancer. Polycyclic hydrocarbons have been found in exhaust smoke from both petrol and diesel engines. This finding is hardly surprising since these compounds are commonly found among products of incomplete combustion but this information has been applied uncritically and with singular lack of a sense of responsibility to the problem of lung cancer No account has been taken of the fact that the quantities of polycyclic hydrocarbons contributed to the air men breathe are extremely small and areindeed insignificant in comparison to the background pollution by coal smoke (Waller, Commins, and Lawther, 1965). Smoke is produced only by maladjusted or over-fuelled diesel engines (a small puff on starting or acceleration is normal) and we have found that even the smoke from dirty overloaded diesel vehicles is one of the poorest sources of polycyclic hydrocarbons.

Some justify their indictment of the diesel by pointing out that the rise in lung cancer has coincided with the increase in the amount of diesel traffic. They ignore the fact that the rise in mortality from lung cancer was already well under way when the diesel engine came into general use in the late 1930s. And again, the coincidence of the later rise in lung cancer with the increase in diesel traffic cannot be construed as a causal relationship since experience with all environmental carcinogens leads one to expect that an exposure of many years is needed before cancer is produced.

From this temporal point of view the petrol vehicle merits more careful consideration since it has been polluting city air for long enough to be suspected of causing the rise in lung cancer. But if this were indeed the case one would expect to see an excess of deaths from lung cancer among people exposed to high concentrations of traffic "fumes." No such excess is seen among garage workers, 
traffic policemen, or indeed any other workers whose job leads them to be exposed unduly to exhaust products.

All the evidence from many parts of the world points to the appearance at about the turn of the century of a new factor which has been spreading to influence firstly men and latterly women in many parts of the world. Few can doubt, having scrutinised the evidence, that this factor is of the smoking of cigarettes. The report of the Royal College of Physicians on "Smoking and Health" (1962) and the report of the U.S. Surgeon General on the same topic will surely come to be regarded as the most important reports affecting the health of the public to be published for many years.

When due allowance has been made for smoking habits there remains evidence that some urban factor is involved in the genesis of lung cancer. Of course, air pollution needs to be considered as the most likely factor but the urban excess (which is declining) over the rural death rate may yet be shown to be due to some artifact such as better diagnostic facilities in towns. Much work, both experimental and epidemiological, remains to be done.

Although it is obvious from present evidence that cigarette smoking rather than air pollution has been responsible for the observed rise in lung cancer, new pollutants must be scrutinised lest they cause a further wave of disease. Asbestos, a widely used mineral, has recently been shown to be more dangerous than was at once thought and the work of Newhouse and Thompson (1965), which demonstrated the prevalence of mesothelial tumours among people with minimal occupational or domestic exposure should dispel complacency.

The Clean Air Act of 1956, passed as a result of the alarm felt after the 1952 London "smog", is a good act in that it aims to abolish smoke which can be abolished. Sulphur dioxide remains as a problem for which there is as yet no economic solution. But during the period when we are still dependent on fossil fuels, with their contaminant sulphur, for heat and power it would seem reasonable to try as far as is practicable to .burn the fuels centrally and disperse the effluents from tall stacks so that they are unlikely to contaminate the air at the level at which it can be breathed. This trend is being followed by the power industries. Until abundant nuclear energy or huge supplies of natural gas release us from dependence on conventional fuels it behoves us to see that combustion is as complete as possible and that pollution of the air at ground level is abated, for whatever the complexities of the case against air pollution it can be truly said that it can be lethal, it never did anyone any good and is always disgusting.

\section{REFERENCES}

Amdur, M. O. (1959): The Physiological Response of Guinea Pigs to Atmospheric Pollutants, Int. J. Air Poll., 1, 170.

College of General Practitioners. (1961): Chronic Bronchitis in Great Britain: a National Survey, Brit. med. J., ii, 973.

Doll, R., Fisher, R. E. W., GAMmon, E. J., GunN, W., HUGHES, G. O., TYRER, F. H., and WILSON, W. (1965): Mortality of Gasworkers with Special Reference to Cancers of the Lung and Bladder, Chronic Bronchitis, and Pneumoconiosis, Brit. J. industr. Med., 22, 1.

Douglas, J. W. B., and Waller, R. E. (1966): Air Pollution and Respiratory Infection in Children, Brit. J. prev. soc. Med., $20,1$.

GREAT BRITAIN. Ministry of Housing and Local Government. (1956): Clean Air Act, 1956. London: H.M.S.O.

LAWTHER, P. J. (1958): Climate, Air Pollution and Chronic Bronchitis, Proc. roy. Soc. Med., 51, 1473.

LAWTher, P. J., Commins, B. T., and WAller, R. E. (1965): A Study of the Concentrations of Polycyclic Aromatic Hydrocarbons in Gas Works Retort Houses, Brit. J. industr. Med., $22,13$.

Newhouse, M. L., and Thompson, H. (1965): Mesothelioma of Pleura and Peritoneum Following Exposure to Asbestos in the London Area, Brit. J. industr. Med., 22, 261.

REID, L. (1958): The Pathology of Chronic Bronchitis in Oswald, N. C. 'Recent Trends in Chronic Bronchitis,' p. 26. London: Lloyd Luke.

Royal College of PHYSICIANS. (1962): Smoking and Health. London: Pitman.

Stuart-Harris, C. H., and Hanley, T. (1957): Chronic Bronchitis, Emphysema and Cor Pulmonale. London: John Wiley.

U.S. Public Health Service. (1964): Surgeon General's Advisory Committee. Smoking and Health. Washington: U.S. Govt. Printing Office.

WAller, R. E., Commins, B. T., and Lawther, P. J. (1965): Air Pollution in a City Street, Brit. J. industr. Med., 22, 128. 